\title{
(1) r. \\ (อ) OPEN ACCESS \\ Technical considerations and tips for using the Tegus remote proctoring system in elective and emergency cases and in webinars
}

\author{
Alexander von Hessling, Tomás Reyes del Castillo 주 , Justus Erasmus Roos, \\ Grzegorz Marek Karwacki
}

- Additional supplemental material is published online only. To view, please visit the journal online (http://dx.doi. org/10.1136/neurintsurg2021-018401).

Radiology and Nuclear Medicine, Luzerner Kantonsspital Zentrumsspital, Luzern, Switzerland

Correspondence to Dr Tomás Reyes del

Castillo, Radiology and Nuclear Medicine, Luzerner Kantonsspital Zentrumsspital, Luzern, Switzerland; tomrdc@ icloud.com

Received 5 November 2021 Accepted 20 January 2022

Check for updates

(c) Author(s) (or their employer(s)) 2022. Re-use permitted under CC BY-NC. No commercial re-use. See rights and permissions. Published by BMJ.

To cite: von Hessling A, Reyes del Castillo T, Roos JE, et al. J Neurolntervent Surg Epub ahead of print: [please include Day Month Year]. doi:10.1136/

neurintsurg-2021-018401

\section{ABSTRACT}

Smart angiography suites (SAS) refer to the incorporation of audio-video technology and internet connectivity into the angiography suite to enable bidirectional communication for teleproctoring. Remote streaming support (RESS) is intended to increase patient safety by supporting interventionalists with limited experience or who are practicing in geographically remote areas. The aim of this review is to describe real-life experience of the Tegus system and to share practical tips concerning its use and setup. We describe the platform itself, settings and integration in our angiography suite. We provide technical tips intended to help new and potential users to achieve an optimal experience for both neurointerventionalists and proctors. We describe both elective cases that we have performed with teleproctoring and emergencies. Lastly, we describe a different room setup and software solutions used in live workshops. Use of teleproctoring enabled involvement of proctors in cases where an already experienced interventionalist needed support in the decision-making process concerning the sizing and deployment of devices with which he was familiar only on a basic level. Excellent video feed quality and instant communication enabled optimal preparation and in vivo implantation of those devices without the need for physical proctors' presence. In emergency cases the system allowed a senior physician to offer support during cases where optimal device sizing is critical. Our usage concept of the rig permitted monitoring of thrombectomy cases by junior physicians. During webinars a remote streaming platform enabled us to conduct workshops that simulated an "on-site" experience as closely as possible during the COVID-19 pandemic.

\section{INTRODUCTION}

Smart angiography suites (SAS) refer to the incorporation of audio-video technology and internet connectivity into the angiography suite to enable bidirectional communication and collaboration for teleproctoring. They can be used in elective and emergency settings. ${ }^{12}$ Teleproctoring is intended to increase patient safety by supporting interventionalists who have not yet performed many procedures or who are practicing in geographically remote areas, and it has been used in other fields of medicine such as surgery. ${ }^{3}$
In neurointervention it has proven to be just as feasible as local support to achieve similar recanalization times but only in simulated neurovascular thrombectomy environments. ${ }^{2}$

The aim of this review is to describe real-life experience of teleproctoring and share practical tips and technical considerations in setting up a remote proctoring system for beginner users and proctors as well as for institutions considering acquiring such a system.

\section{TEGUS DESCRIPTION AND RIG SETUP}

The Tegus platform (Tegus Medical, Hamburg, Germany) is a low-latency, high-resolution technology for teleproctoring. The system includes a $360^{\circ}$ rotatable, $90^{\circ}$ tiltable, high-definition network camera $(1920 \times 1080$ pixel resolution, 30 fps, $10 \times$ optical zoom, $60 \times$ digital zoom) placed on a transportable pentapod. The viewing angle, zoom and exposure functions can be remotely controlled on the proctor's side. The treating interventionalist can communicate with a proctor via a hands-free headset. Access to the platform requires a user account and an invitation to participate in the session, and the electronic Protected Health Information (ePHI) is secured by encryption. ${ }^{4}$ Physical installation is simple but the issue of connectivity could be complex and requires the support of the local health information technologist (IT) prior to the decision to purchase a teleproctoring system. In order not to trip over the cables running from the Tegus platform to the power and network outlets, taping them to the ground should be considered to ensure room safety and rig stability.

\section{CONSIDERATIONS DURING INITIAL SETUP}

The Tegus platform allows for very good to excellent video quality independent of lightning conditions in the operating room, although surgical spotlights pointing at the table, as well as sudden light changes, should be avoided. The second point is especially important, as some angio suites are set up to darken the ambient light if radiation is on.

The Tegus platform is delivered with two Bluetooth headsets. In our experience, the first operator should put the headset in his left ear and the second operator or technician in their right ear so that they both hear a proctor and can still 


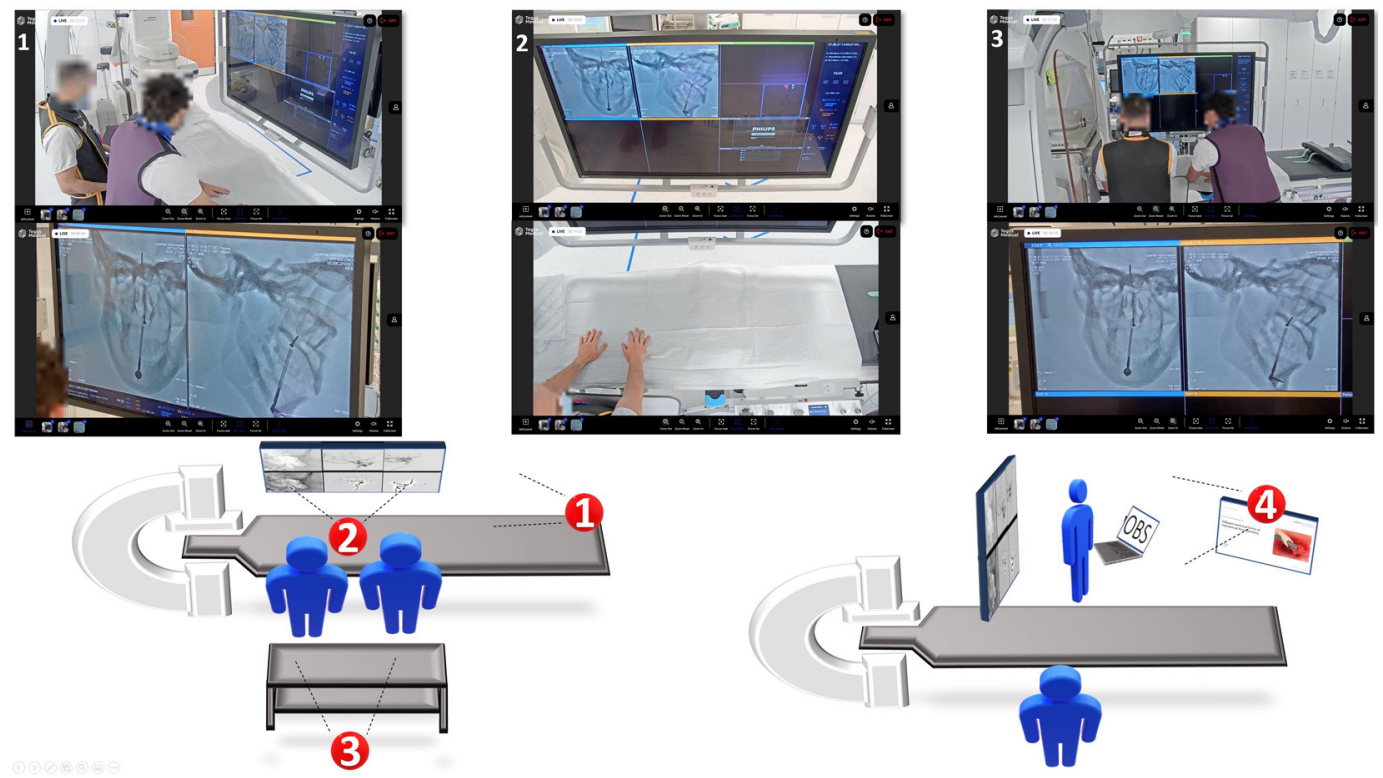

Figure 1 Illustration showing the discussed positions of the Tegus camera in the angio suite. Position 1, our default position, allows for a good overview of the working area, (upper screenshot) but still enables a good representation of the fluoroscopy screen, despite slight geometric distortion (lower screenshot). Position 2, simulating camera placement on a rail above the head of the operator, allows for a superb assessment of the working area as well as a very good depiction of the whole screen, with minor geometric distortion. Position 3 does not allow a free direct view of the angio table but does not introduce any geometric distortion in the zoomed-in view. A disadvantage of this position is potential obstruction by the heads of the operators. To at least partially resolve this issue we advise placing the camera at a height of 2.2-2.5 meters above ground level. Position 4 was used for webinars/workshops with the angio screen at a $90^{\circ}$ angle to the long axis of the table and a separate screen under the camera for live view of the feed. A separate computer with Open Broadcaster Software (OBS) software enabled control of multiple camera feeds.

communicate with each other. It is also worth notifying other medical personnel in the room about a running session so that they do not get confused about loud verbal communication. Independent of the audio input method, the proctor should ensure that he is alone in the room and that there are no interruptions during the session. Background communication on the proctoring side can be very disturbing for the operator and could lead to confusion if the subject overlaps with a running case (discussion about materials and medications at the proctor's site).

The camera position should emulate a potential reallife proctor presence. In our angio suite, we concluded that three positions are feasible (figure 1). Position 1 (diagonal or towards the feet of the patient) does not interfere with table and personnel movement, and despite a relatively large distance to the screen, allows for good zoomed-in views as well as a good overview room visualization. Conversely, a geometric distortion of angio screens is introduced, meaning that the closer vertical edge is higher than the remote vertical edge, distorting the image. However, we have not found this to impair the procedure in any way. Experimental position 2 (above the operators, on a rail) enables a top-down view of the patient and the side table which is optimal for preparing devices that require close proctor inspection. Position 3 enables a direct zoomed-in view between the first and second operators with almost no geometric distortion. A disadvantage is the necessity of maintaining the distance between the two operators, allowing for a clear view line for the camera towards the monitor. We have found that the camera should always be elevated to 2.2-2.5 meters above ground level, allowing for a slight overhead angle towards the angio screens above the head levels of the personnel present.

\section{PREPARING A SESSION}

Good practice involves a prior video session to familiarize oneself with the proctor and to discuss the treatment options. It is of paramount importance to start the Tegus platform hardware and to wait about 5 min before the session itself starts or proctors and viewers try to join in. Sessions can be scheduled either through a web page or through an app on a mobile phone. All potential users are required to create an account on the manufacturer's webpage. To create a session, one must choose a name for it, invite proctors and viewers, and set a time and date. Best practice involves including a short description of the case (at the time of writing no images can be attached). In emergency cases created via the website, since the system currently allows invitation of one proctor, we suggest choosing potential proctors as viewers and including a direct telephone number to the interventionalist in the description so that any available proctors can signify their availability by telephone and be invited later and control the session. If an app on a mobile device is used to create an emergency session, many potential proctors can be invited, and the first to join will automatically be able to control the camera and communicate with the treating physician.

Proctors (and viewers) are notified about an upcoming or a running session on the app directly on their mobile device and by email. In order to join a session, they must (at the time of writing) use the Google Chrome or Edge web browser; other web browsers, as well as mobile browsers, are not supported. In our experience, proctoring a session on a laptop or a regular PC are both possible, although having a mouse connected enables for easier, more precise control of the camera and preset setup. A dedicated microphone or a headset are recommended. 


\section{RUNNING A SESSION}

After joining the session, bilateral confirmation of goodquality audio and video communication should be established. The proctor should check if the rig position is satisfactory, if the camera can be controlled (movement, zooming, focus and brightness), as well as setup presets (ie, overview, zoomed-in view of the screens and zoomed-in view of the side table). Any audio issues must be resolved before proceeding with the session. Operators should in particular set the desired volume on the headsets (with the help of unsterile personnel) to ensure clear reception of the proctor's voice. During the session, the need to change the position of the rig from the proctor's side, as well from on-site personnel, must be clearly stated. Even a small, sudden movement of the mast that carries the camera can produce a very disturbing wobble, and any rotation of the rig can render the previously setup presets unusable. Screen layout is of great importance. In our experience, the default factory layout of our angiography system is not optimal for Tegus-assisted interventions, since the output of the A-plane is situated above the B-plane's video feed. Due to the video format (widescreen) of the camera, it is better to place the outputs next to each other so that they are better suited for remote sessions. If a monoplane system is used, the best option is to place a reference image beside the main feed.

\section{TIPS FOR SUCCESSFUL PROCTORING}

From a technical point of view, the most important aspect is the optimal placement of the camera and keeping in mind that the preparation steps of a chosen device must be performed in clear view for the proctor and thus potentially not on the angiographic table itself. Depending on the position of the rig, extra care should be taken by the treating physician not to obstruct the camera's view; in particular, the typical "leaning in" movements when performing maneuvers under high magnification should be limited (depending on the camera position).

\section{APPLICATIONS}

\section{Remote proctor experience in emergency cases}

During an emergency case of a ruptured aneurysm, an email or notification on the smartphone informed the potential proctors about a request for assistance. One of the addressed physicians contacted the neurointerventionalist by telephone, confirming his availability. The treating physician quickly edited the running session on the Tegus website, changing the status of the available senior physician from "viewer" to "proctor". The rig with the camera was placed in position 1 (figure 1). On connecting, the proctor quickly confirmed the quality of the bilateral audio communication and ensured that he could move the camera and control the zoom level. After the presentation of the already performed angiographic runs and of the 3D DSA, he discussed the treatment strategy and the crucial sizing of the chosen endoluminal device. During the positioning of the intra-saccular flow-disruptor, a high level of zoom was required to visualize the proximal and distal markers for both the operator and proctor.

\section{Setup for online webinars/workshops}

We have live-streamed multiple sessions relating to many aspects of aneurysm treatment in neuroradiology. Some advanced techniques (balloon and stent-assisted coiling) could be presented in almost natural conditions by transmitting the fluoroscopy feed over the Tegus. The camera rig was placed in position 4 (figure 1), but on the left side of the table, opposite to the physician and technician. In a zoomed-out view, the camera could show the whole room and, if necessary, allowed for a close-up view of the angio table. A separate screen was placed behind the Tegus rig. This enabled us to have a live view of the feed being transmitted online and to see the slides of presentations, while looking almost directly at the camera, in order to maintain the appearance of speaking directly to the participants. The disadvantage of this position is the need to turn the fluoroscopy screen in a $90^{\circ}$ angle to the long axis of the table (figure 1), which is not optimal for the operator, allowing simulation of a direct feed from the angiography device itself. We found that using an opensource program called Open Broadcaster Software (OBS) was crucial in creating and streaming the workshops. OBS allows for controlling numerous video captures and viewing them in predestined, resizable windows on a computer screen. ${ }^{5}$

\section{Limitations}

In comparison to the normal on-site experience, we did sometimes find that a view of the proctor's face was missing for receiving non-verbal clues which could carry additional treatment-related information based on the research in other fields. ${ }^{6}$ Teleproctoring requires an already experienced treating physician who can deploy instructions from proctors (ie, unsheathe, straighten the system) without going into the details of those maneuvers. The on-site interventionalist should be able to handle potential complications and in the best case scenario be able to provide alternative treatment to the one she/he is begin proctored for. The stationary position of the camera can be limiting as in a reallife scenario the proctor can change his position or even stand directly at the table and potentially have both the screens and devices in close view.

\section{CLOSING REMARKS}

Current technical developments allow for high-quality, remote proctoring, although some adjustments and considerations (as discussed here) are necessary to ensure an optimal experience in both elective and emergency cases as well as in webinar settings.

\section{Twitter Tomás Reyes del Castillo @tomrdc}

Acknowledgements The authors want to thank Tegus Medical for the support provided during this study.

Contributors $\mathrm{AvH}$ was the main author of the manuscript. TRdC was a major contributor to writing the manuscript. JER and GK provided administrative support and a critical review of the intellectual content of the manuscript. All authors read and approved the final manuscript.

Funding The authors have not declared a specific grant for this research from any funding agency in the public, commercial or not-for-profit sectors.

Competing interests None declared.

\section{Patient consent for publication Not applicable.}

Ethics approval All procedures performed in studies involving human participants were in accordance with the ethical standards of the institutional and/or national research committee and with the 1964 Helsinki declaration and its later amendments or comparable ethical standards. Informed consent was obtained from all individual participants included in the study.

Provenance and peer review Not commissioned; externally peer reviewed.

Open access This is an open access article distributed in accordance with the Creative Commons Attribution Non Commercial (CC BY-NC 4.0) license, which permits others to distribute, remix, adapt, build upon this work non-commercially, and license their derivative works on different terms, provided the original work is properly cited, appropriate credit is given, any changes made indicated, and the use is non-commercial. See: http://creativecommons.org/licenses/by-nc/4.0/.

\section{ORCID iD}

Tomás Reyes del Castillo http://orcid.org/0000-0002-3080-1568 


\section{REFERENCES}

1 Lim DZ, Mitreski G, Maingard J, et al. The smart angiography suite. J Neurointerv Surg 2022;14. doi:10.1136/neurintsurg-2021-017383. [Epub ahead of print: 1507 2021].

2 Bechstein M, Buhk J-H, Frölich AM, et al. Training and supervision of thrombectomy by remote live streaming support (RESS) : randomized comparison using simulated stroke interventions. Clin Neuroradiol 2021;31:181-7.

3 Huang EY, Knight $S$, Guetter CR, et al. Telemedicine and telementoring in the surgical specialties: a narrative review. Am J Surg 2019;218:760-6.
4 Bechstein M, Elsheikh S, Wodarg F, et al. Interhospital teleproctoring of endovascular intracranial aneurysm treatment using a dedicated live-streaming technology: first experiences during the COVID-19 pandemic. BMJ Case Rep 2020;13:e016722.

5 Kaufmann D. Using OBS to create video lectures for online counseling students. J Instruction Res 2019;8:70-6.

6 Tiferes J, Hussein AA, Bisantz A, et al. Are gestures worth a thousand words? Verbal and nonverbal communication during robot-assisted surgery. Appl Ergon 2019;78:251-62. 